\title{
Particularități morfosintactice ale indefinitului tot în limba română veche
}

\author{
Isabela Nedelcu* \\ Facultatea de Litere, Universitatea din București, Str. Edgar Quinet 5-7, Sector 1, 010017 București, România \\ Institutul de Lingvistică „Iorgu Iordan - Al. Rosetti”, Calea 13 Septembrie 13, 050711 București, România
}

\section{Despre articol}

Istoric:

Primit 26 mai 2017

Acceptat 3 iunie 2017

Publicat 30 septembrie 2017

Cuvinte-cheie: pronume indefinit adjectiv indefinit cuantificator română veche variație

\begin{abstract}
Rezumat
În acest articol se stabilesc și se discută, prin raportare la limba actuală, o serie de particularități morfosintactice ale indefinitului tot în limba veche: forme care s-au pierdut, modalități mai multe (sintetică, analitică și mixtă) de exprimare a genitiv-dativului singular și plural, topica mai permisivă și posibilitatea de a se construi cu un substantiv nearticulat. Descrierea particularităților gramaticale ale cuantificatorului tot evidențiază o mare variație: (i) între realizarea sintetică, realizarea analitică și cea mixtă a genitiv-dativului (toatei + substantiv la genitivdativ, a/la/de toată + substantiv cu formă de nominativ-acuzativ, a toată + substantiv la genitiv-dativ); (ii) între forma (pronominală și adjectivală) cu particula finală - $a$ și cea fără - a (tuturor, tuturora; tuturor oamenilor, tuturora fraților); (iii) între postpunerea și antepunerea lui tot în raport cu anumite pronume (ei toți, toți ei); (iv) între structura cu substantiv articulat și cea cu substantiv nearticulat (toate zilele, toate zile). Comparația cu limba actuală arată că, în unele cazuri, variația a fost eliminată, iar în altele se păstrează.
\end{abstract}

\section{Introducere}

Pronumele și adjectivul pronominal indefinit tot, cu rol de cuantificator universal, prezintă, în limba veche (secolele al XVI-lea - al XVIII-lea), o serie de particularități morfologice și sintactice, dintre care cele mai evidente vor fi semnalate şi discutate în articolul de faţă.

Contextele extrase din corpusul de limbă veche ilustrează atît valoarea globalizantă a cuantificatorului universal tot (1a), cît și valoarea distributivă, care apare atunci cînd acesta se construiește cu un substantiv la singular utilizat generic, fiind sinonim cu fiecare (1b) (vezi Giurgea, 2013, p. 169; Stan, 2016b, p. 352 pentru valoarea de cuantificator universal distributiv a lui tot antepus substantivului).

(1) a. cistitul împărat și cu tot svatul și cu toată țara măriii lui și cu toț domnii creștinești să aibă a îmbla și a griji pentru nevoia mea, toți să mă scumpere den robie (Dî.1600, XXXIV)

b. tot creștinul, oare păcătos, oare dirept, are cineș îngerul său socotitoriu (CazV.1643, 22 $\left.{ }^{\mathrm{r}}\right)$

\section{Particularităţi morfologice ale pronumelui și ale adjectivului pronominal tot}

Ca și în limba actuală, indefinitul tot distinge forme în funcție de gen și număr: tot m.sg., toată f.sg., toți m.pl., toate f.pl. Diferențe—parțiale—față de limba actuală se înregistrează în exprimarea cazurilor oblice. Aceste diferențe apar numai la genitiv-dativ singular, pentru că la genitiv-dativ plural în cele două perioade ale limbii forma este identică: tuturor(a). Astfel, dacă în limba actuală tot nu are formă de genitiv-dativ singular, în limba veche acesta cunoaște, în ipostaza adjectivală, forma de feminin toatei (2a-e), atestată la sfîrșitul secolului al XVII-lea și începutul secolului al XVIII-lea (Pană Dindelegan, 2013, p. 166-167), în texte originale și traduse ${ }^{1}$.

*Adresă de corespondență: isabela.nedelcu@yahoo.com.

${ }^{1}$ Forma adjectivală toatei este întîlnită încă, dar foarte rar, în secolul al XIX-lea (Croitor, 2015, p. 149). 
(2) a. făcătoriu a toatei ființe, Dumnezeu (FN.1693-704, 69)

b. otcîrmuitori romani toatei Dachii (CIst.1700-50, 24 ${ }^{\mathrm{r}}$ )

c. voievodul toatei Ghermanii (CIst.1700-50, 79v)

d. au mijlocit viața a toatei lumi $\left(\mathrm{AD} .1722-5,167^{\mathrm{r}}\right)$

e. ajutoriul a toatei oști (BVs.1763,21 $\left.{ }^{\mathrm{v}}\right)$

Forma de genitiv-dativ masculin singular totului este rară și se întîlnește în îmbinări precum cu totului, cu totului tot, de totului tot $(3 \mathrm{a}-\mathrm{c})^{2}$.

(3) a. Trupurile lor întregi cu totă carnea și pelița, cum ar hi de vro lună adormiți și zvîntați, palmele, unghile, urechile, nasul, cu totului întregi, neprăbușiți (DVs.1682-6, 487v )

b. Iar altă oaste, cîtă au avut Șfedul în Țara Căzăcească, doo obuzuri, cu totul au luat-o moscalii, cu ghenărari, cu ofițeri, cu cară, cu pușci, cu totului tot și cu multă avere (NL 1750-66, 187)

c. Împărțirea căsașilor cînd să va face pentru aceaste vini (...) să înțeleage să fie pănă la o vreame, iară nu de totului tot (Prav.1646, 115)

Mai frecventă—și înregistrată încă din primele texte—este modalitatea analitică de exprimare a genitivdativului singular în grupul nominal conținînd pe prima poziţie cuantificatorul tot, situație în care intervin prepoziția a (cel mai adesea) ( $4 \mathrm{a}-\mathrm{g})$ și la pentru exprimarea genitiv-dativului ( $4 \mathrm{~h}-\mathrm{i})$ sau de pentru exprimarea genitivului (4j), iar tot are formă de nominativ-acuzativ. În multe texte, precum PH.150010, Dî, CC ${ }^{1} .1567$, MC.1620, șT.1644, svi 1670, genitiv-dativul singular feminin al lui tot se exprimă exclusiv analitic. În alte texte, forma toatei este fie inferioară numeric realizării prepoziționale a relației de genitiv-dativ (de pildă, în BVs.1763, toatei are 27,59\% din atestări și a/la/de toată, 72,41\%), fie inexistentă sau, dimpotrivă, singura variantă de utilizare (în CDicț.1691-7, apare numai gruparea prepozițională, nu și toatei, în schimb, în FN.1693-704, se întîlnește toatei de opt ori, nu și gruparea prepozițională, în CIst.1700-50, se găsește numai toatei de două ori, nu și gruparea prepozițională).

(4) a. peirea a toată creștinătatea (Dî.1600, XXXIII)

b. împărat a tot pămîntul (PH.1500-10, 40 $)$

c. Dat-au hrană a toată pelița (PH.1500-10,116 r)

d. împăratul a totu iaste Tatăl nostru den ceriu $\left(\mathrm{CS}_{\mathrm{xv}} \cdot 1619,122^{\mathrm{r}}\right)$

e. naintea a toată curtea (MC.1620, $\left.44^{\mathrm{v}}\right)$

f. nește începături a tot rrăul $\left(\right.$ Svi $\left.\sim 1670,257^{\mathrm{r}}\right)$

g. veni-va Hristos, Dumnezeul nostru, să judece a toată lumea (svi 1670, 60v)

h. au dat poroncă la toată boierimea (NL 1750-66, 386)

i. toate le-au împărțit la toată oastea (BVs.1763, 140v)

j. $\quad$ asupra de tot copaciul (DPar.1683, II/ $\left./ 8^{\mathrm{r}}\right)^{3}$

În ceea ce privește genitiv-dativul plural, ca și în limba actuală, în limba veche, se utilizează forma sintetică (pronominală sau adjectivală), care prezintă desinența - or $(5 a-c)$.

(5) a. desupra tuturora (Dî.1600, XXXII)

b. Faraon dzise tuturor eghipteanilor (PO.1582, 145)

c. să facă voia tuturor dracilor $\left(\mathrm{NT} .1648,192^{\mathrm{r}}\right)$

Forma sintetică de genitiv-dativ plural este concurată (la fel ca cea de genitiv-dativ singular) de construcția cu prepoziția $a(6 \mathrm{a}-\mathrm{d})$, sau, mai rar, la (6e) ori de (pentru exprimarea genitivului) (6f), urmată de tot (și de substantiv) la forma de nominativ-acuzativ.

\footnotetext{
${ }^{2}$ Îmbinări precum cu totului, cu/în totului tot sînt atestate rar și în secolul al XIX-lea (Croitor, 2015, p. 149-150).

${ }^{3}$ De observat că în structura cu de pentru marcarea genitivului, prepoziția este urmată de un grup nominal determinat definit. Acest tip de structură s-a pierdut.
} 
(6) a. rădăcina a toate bunătățile iaste dragostea $\left(\mathrm{CC}^{2} .1581,47\right)$

b. judecătoriu a toți, viiloru și morțiloru $\left(\mathrm{CC}^{2} .1581,509\right)$

c. duminica a toți sfinții $\left(\mathrm{CS}_{\mathrm{IV}} \cdot 1590-602,36^{\mathrm{v}}\right)$

d. denaintea a toți (svi 1670, 227 $)$

e. zîoa cea dintîi la toate lunile (CDicț.1691-7,276)

f. cărticică însămnătoare de toate lucrurile zilești (CDicț.1691-7, 159) $)^{4}$

Forma pronominală de genitiv-dativ plural include, dar nu obligatoriu, particula finală $-a$, la fel ca în limba actuală [de comparat $(7 a-b) c u(8 a-d)]$. În multe texte, formele pronominale cu $-a$ final și fără $-a$ coexistă (Dî, CC ${ }^{1} .1567$, MC.1620, sVI 1670, DPar.1683, CLM.1700-50, BVs.1763); mai rar se utilizează o singură formă (de pildă, în PH.1500-10, șT.1644 și Prav.1780, apare numai tuturor, folosit ca pronume, dar şi ca adjectiv).

(7) a. da tuturora den dăstul toate (Svi 1670, 262 $)$

b. Tuturora această mustrare făcea (CLM.1700-50, 177 $)$

(8) a. fața tuturor unul cătră alalt să stea (Po.1582, 262)

b. Facem de scire tuturoru (Dî.1593, CXIII)

c. ziditoriul tuturor (șT.1644, 203)

d. Însă nu era cu știrea tuturor pentru Dabijea vodă (CLM.1700-50,318 $)$

În schimb, forma adjectivală de genitiv-dativ plural se comportă diferit față de limba actuală (care nu acceptă finala $-a$ : *tuturora copiilor), fiind înregistrată în textele de limbă veche atît fără $-a(9 a-b)$, cît și cu $-a(10 \mathrm{a}-\mathrm{d})$. În unele texte din corpusul utilizat, se întîlnește numai tuturor adjectival (Dî, PH.150010, MC.1620, șT.1644, DPar.1683, Prav.1780), iar în altele, se găsesc atît tuturor, cît și tuturora în ipostază adjectivală (CC ${ }^{1} .1567$, PO.1582, NT.1648, svi 1670, BVs.1763).

(9) a. înaintea tuturor oamenilor $\left(\mathrm{CC}^{1} .1567,128^{\mathrm{r}}\right)$

b. izvorul a tuturor răutăților (CLM.1700-50, 239 $)$

(10) a. au porîncit apostolilor şi tuturora popilor (CM.1567, 255 $5^{\mathrm{r}}$ )

b. făcea bucurie mare tuturora fraţilor (NT.1648, 154 ${ }^{\mathrm{v}}$ )

c. Știi cîte făcuiu celora ce se chema călugări și tuturora creștinilor? (svi 1670, 19 ${ }^{\text {r }}$ )

d. imperator al tuturora părților lumii (BVs.1763, 107 ${ }^{\mathrm{r}}$ )

În limba actuală, particula - $a$ marchează absența grupului determinat definit și distinge la genitiv-dativ plural pronumele indefinit tot de adjectivul indefinit. Elementul nominal vid presupus de pronumele tuturora poate fi recuperat, atît în limba actuală, cît și în limba veche, prin raportare la un antecedent (11a) sau, în afara unui antecedent, poate primi o interpretare generică (11b) (vezi Giurgea, 2010, p. 169-171 pentru interpretarea elementului vid ca pro- $N$ și pentru citirile posibile ale acestuia).

(11) a. împle sacii acestor oameni $\mathrm{i}_{\mathrm{i}}$ cu grîu, atîta cît vor putea duce şi banii tuturora $\left[\varnothing_{\mathrm{i}}\right]$ pune desupra în sacii lor (Po.1582, 155)

b. Soarele dereptu iaste Dumnezeu, cumu iaste scrisu că tuturora [Ø] întru un chipu luminează lucirea dulceției sale $\left(\mathrm{CC}^{2} .1581,439\right)$

Structurile conținînd o formă adjectivală cu particula $-a$ și un nume determinat definit arată că, în limba veche, finala $-a$ nu presupune în mod necesar o elipsă (un pro- $N$ ). Și în alte structuri din limba veche, cum sînt cele cu indefinitul fiecare (12a) sau cu relativul care (12b), forma adjectivală de genitiv-dativ poate avea, spre deosebire de limba actuală, finala - $a$ (la fel ca forma pronominală).

\footnotetext{
${ }^{4}$ În legătură cu exemplul (6f), înregistrat de Pană Dindelegan (2013, p. 168), autoarea atrage atenția că grupul nominal în genitiv are trăsătura [+ Definit], iar de este selectat de un adjectiv postverbal derivat în -tor.
} 
(12) a. Cu greu și cu strimt iaste neștine a da cap și începătură fieștecăruia lucru (CIst.1700-50, $\left.1^{\mathrm{r}}\right)$

b. au tăbărît în coasta unui deal, ce ai lui oameni mai nainte îl cuprinsease, deasupra căruia deal, trimiţîndu-se viglele, să putea dăscoperi și a vedea oastea nepriiatenului (BVs.1763, $77^{\mathrm{v}}$ )

Cînd tot este primul component al grupului nominal, exprimarea genitiv-dativului singular sau plural cunoaște și o marcare mixtă, prin prepoziția $a$ și flectivul de genitiv-dativ atașat radicalului substantival $(13 \mathrm{a}-\mathrm{g})^{5}$. În asemenea structuri, care s-au pierdut, cazul se exprimă redundant, la ambii componenţi ai grupului nominal. Repetarea trăsăturii de caz este posibilă în limba veche și în alte structuri, cum sînt cele în care articolul marchează cazul la mai multe componente ale grupului (14) (Stan, 2016a, p. 291-292).

(13) a. Și-l puse domnu caseei sale și giudețu a toată agonisiteei sale (PH.1500-10, 88 $)$

b. gice a toți creștinilor $\left(\mathrm{CC}^{1} .1567,6^{\mathrm{v}}\right)$

c. muma a toți viilor (Po.1582, 21)

d. Și dziseră Moisi și Aron a toți fiilor lu Israil (Po.1582, 231)

e. sîntem slugi credincioase a toată creștinătăței (Dî.1600, XLIV)

f. înaintea a tot săborului (AD.1722-5, 127 ${ }^{\mathrm{v}}$ )

g. cu multă păreare rea a tot norodului creștinescu (BVs.1763,102 $)$

(14) cinstitului și preaosfințitului părintelui nostru arhiepiscop (DRH,B.1653, 14, apud Stan, 2016a, p. 291)

\section{Particularități sintactice ale indefinitului tot}

Și în ceea ce privește comportamentul sintactic al indefinitului tot se constată, pe de o parte, asemănări cu limba actuală, pe de altă parte, oscilații şi particularități numai ale limbii vechi.

\subsection{Topica indefinitului tot}

Ca și în limba actuală, indefinitul tot poate apărea atît antepus (15a), cît și postpus grupului nominal $(15 \mathrm{~b}-\mathrm{c})$ (despre posibilitatea de deplasare a cuantificatorului tot, calificat drept „flotant” sau „extern”, vezi Stan, 2015, p. 599; Nicolae, 2016, p. 152).
a. toate slugile lui $\left(\mathrm{CS}_{\mathrm{XI}} \cdot 1583-619,94^{\mathrm{r}}\right)$
b. chemă slugile lui toate $\left(\mathrm{Cs}_{\mathrm{XI}} \cdot 1583-619,96^{\mathrm{v}}\right)^{6}$
c. sfinţii toți $\left(\mathrm{CS}_{\mathrm{IV}} \cdot 1590-602,36^{\mathrm{v}}\right)$

În limba veche, topica lui tot este mai permisivă, cuantificatorul putîndu-se deplasa în poziții pe care astăzi nu le mai acceptă, ca în exemplele (16a-e), unde tot este antepus unor pronume (16a-d) sau postpus (16e). În astfel de structuri, mai frecventă este topica pe care o întîlnim și astăzi $(17 a-c)$.

(16) a. toți voi (CL.1570, 34v apud Stan, 2016b, p. 352)

b. Toți voi vă veți sminti în Mine în ceastă noapte (NT.1648, 35

c. căzu frică spre toți ei $\left(\mathrm{NT} .1648,160^{\mathrm{v}}\right)$

d. Pentru cari toate aceaste pricini tuturor dumneavoastră trebuie a fi cunoscut (BVs.1763, $15^{\mathrm{v}}$ )

e. În acest chip fu dat lui Avraam ocină lui pămîntul lui Efron (...) pre vedearea feciorilor lui Het și acelora tuturora, carii intra și eșiia pre poarta orașului lor (Po.1582,74)

\footnotetext{
${ }^{5}$ Acest tip de marcare are reminiscențe în secolul al XIX-lea (Pană Dindelegan, 2013, p. 169; Nedelcu, 2015, p. 56).

${ }^{6}$ În limba actuală, se întîlnesc structuri similare: rudele lui toate (internet).
} 
(17) a. Împreună întru alu mieu liubovu împreunai pre voi, cumu iaste și urîciunea împreună spre voi toți $\left(\mathrm{CC}^{2} .1581,470\right)$

b. ei toți giudecară pre El a fi vinovat morției $\left(\mathrm{NT} .1648,61^{\mathrm{v}}\right)$

c. zise Iacov caseei sale și tuturor acelora carii era cu el (Po.1582, 119)

O explicaţie pentru topica lui tot în raport cu anumite pronume, diferită de cea din limba actuală, poate fi influența textului original (de pildă, aşa cum se arată în Stan, 2016b, p. 352 referitor la exemplul (16a), poziția cuantificatorului tot se explică prin traducerea după slavonă).

Tot a pierdut de asemenea disponibilitatea de a apărea după indefinitul alternativ alt, atît în grupul nominal cu nume exprimat (18a), cît și în cel cu elipsa numelui $(18 b-c)$. În limba actuală, este posibilă numai gruparea cu indefinitul alte „articulat” după toate (toate altele) ${ }^{7}$.

(18) a. Hatmanii amîndoi au cădzut la robiie, Sinavschii și alte toate capete (CLM.1700-50, 246 ${ }^{\mathrm{r}}$ )

b. alte toate va tocmi Dumnezeu (Dî.1593, XCIII)

c. Ceteaște și alte toate $\left(\mathrm{CC}^{1} .1567,182^{\mathrm{v}}\right)$

\subsection{Articularea/nearticularea substantivului cu care se construiește tot}

Ca și în limba actuală, în limba veche, cuantificatorul tot cere ca substantivul—la singular sau la plural— cu care se combină să fie determinat definit, adică să fie însoțit de un articol definit enclitic $(19 a-b)$ sau de alt determinant definit $(19 c-e)$. Această condiție nu este respectată însă sistematic în limba veche, tot putînd selecta și un substantiv nearticulat (20a-p).

(19) a. totu omulu e ca iarba $\left(\mathrm{CC}^{2} \cdot 1581,221\right)$

b. Dumnezeu să iarte greșalele ce greșimu noi în toate zilele și în toate ceasurile $\left(\mathrm{CC}^{2} .1581,47\right)$

c. toțicei oameni $\left(\mathrm{CC}^{1} .1567,146^{\mathrm{v}}\right)^{8}$

d. semînțeei tale voiu da toate aceaste ținuture (po.1582, 85)

e. toț alalți boiari (Dî.1599, XVIII)

(20) a. spăl în toate nopți așternutulu mieu (PH.1500-10, $4^{\mathrm{r}}$ )

b. cu toată usîrdie numai ale lu Dumnezeu învățături să facemu $\left(\mathrm{CC}^{2} .1581,466\right)$

c. noi toți-lu așteptămu în toate zile $\left(\mathrm{CC}^{2} .1581,108\right)$

d. Și împlu Domnedzeu în a șaptea zi lucrul său ce făcu și odihni în a șaptea dzi, de toate lucrure ce era făcut (Po.1582, 15)

e. Luo iară Isau muierile sale, feciorii și featele sale și toate suflete din casa sa (po.1582, 123)

f. Culegea derept însă den ea în toate demîneți cît putea fi destul pre mîncare (Po.1582, 233)

g. Noi ce-am putut amu făcut și isprava ți-am tremes în tot chip pre Iurgachi (Dî.1593, XCIII)

h. nu-l putea toată lume birui (FD.1592-604, 484 $4^{\mathrm{r}}$ )

i. el usucă toată iarbă și toț copacii și toată frundză (FD.1592-604, 499')

j. Svînta Besearică ce să amesteca în toată vreamea și în toate dzile (șT.1644, 238-239)

k. Spăla-voiu în toate nopți patul mieu (svi 1670,96 ${ }^{\mathrm{r}}$ )

1. acolea de față <este> mărturie toată oaste îngerească (SVI 1670, 181 $\left.{ }^{\mathrm{r}}\right)$

m. Cade-să tine în toate vremi a cînta în toate glasuri cuvioase, Fiiule a lui Dumnădzău (DPar. $1683, \mathrm{IV} / 9^{\mathrm{r}}$ )

n. au trimis soli pe la toate țări creștine (CLM.1700-50, 191 ${ }^{\mathrm{r}}$ )

o. îmbla în tot cias, cum să dzice, cu dzilele a mînă (CLM.1700-50, 176 r)

p. N-au lipsitu nemică den toate podoabe (CLM.1700-50,237 $)$

\footnotetext{
${ }^{7}$ Referindu-se la perioada 1521-1640, Frâncu (2009, p. 69) apreciază că o caracteristică a acesteia este folosirea frecventă a formelor „nearticulate” ale pronumelui alt.

${ }^{8}$ Asocierea directă a articolului demonstrativ cel cu substantivul nu mai este posibilă în limba actuală (e posibilă însă o structură ca toți cei trei oameni).
} 
În structura care conține un adjectiv antepus substantivului (21a-b), se constată de asemenea oscilații de articulare, față de limba actuală, unde adjectivul este obligatoriu articulat [ca în (21a)].
a. toate blagosloveştile glasuri (svi $1670,163^{\mathrm{r}}$ )
b. Toată trupească mîngîiare șî răpaos, pănă în sfîrșit o arunca (SVI 1670, 102 r)

Oscilații de articulare apar și cînd structura include un cuantificator numeric (22a-b), situație în care limba actuală a păstrat doar posibilitatea ca substantivul precedat de un astfel de cuantificator să fie articulat [ca în $(22 a)]$.

(22) a. Și supt toate doo creangurile cîte un bumb să fie (Po.1582, 263)

b. în toate șapte zile (svi 1670, 270 $)$

Așa cum se observă în exemplele (20a-p), (22b), nearticularea substantivului postpus lui tot se regăsește atît în texte originale, cît și în texte traduse. Pentru explicarea formelor nearticulate din construcția cu tot, întîlnite mai frecvent în secolul al XVI-lea, trebuie luată în considerare influența modelelor străine (vezi Stan, 2015, p. 600 și bibliografia). De pildă, inexistența articolului în slavonă este relevantă pentru o serie de texte în care substantivul însoțit de tot este nearticulat.

Analizînd în perspectivă tipologică și diacronică distribuția cuantificatorului tot în raport cu articolul definit, Stan (2015) arată că româna a pierdut tiparul fără articol, întîlnit și în alte idiomuri vechi romanice.

Structurile fără articol din limba veche pot fi referențiale-în poziții argumentale sau după prepoziție $e^{9}$ - dar și nereferențiale (vezi Stan, 2015, p. 600 pentru lectura referențială și nereferențială a structurilor cu tot + substantiv nearticulat). Nearticularea, ca și articularea substantivului din structura cu tot, nu ține seama de distincția generic (23a) vs nongeneric (referențial) (23b).

a. În toate dzile miluiaște şi împrumut dă dereptul și săm<î $>$ n̦ta lui în blagoslovenie va fi (PH.1500-10, 32 $2^{\mathrm{r}}$ )

b. Fură lacrămile meale mie pînre dzua și noaptea cîndu grăiia mie în toate dzile (PH.1500-10, $35^{\mathrm{v}}$ )

\section{Concluzii}

Aspectele morfosintactice semnalate-ilustrate atît de textele originale, cît și de cele traduse-dovedesc variația mare de comportament a indefinitului tot în limba veche, variație care s-a diminuat pînă în limba actuală, păstrîndu-se doar în unele situații, iar în altele dispărînd.

La nivel morfologic, variația privește, pe de o parte, modalitățile concomitente sintetică, analitică și mixtă de marcare a cazurilor oblice la singular (toatei + substantiv la genitiv-dativ, a/la/de toată + substantiv cu formă de nominativ-acuzativ, a toată + substantiv la genitiv-dativ) şi la plural (tuturor (a), a/la/de toți/toate + substantiv cu formă de nominativ-acuzativ, a toți/toate + substantiv la genitiv-dativ), pe de altă parte, includerea inconsecventă a particulei finale - $a$ în structura formei de genitiv-dativ plural. În limba actuală, variaţia în realizarea genitiv-dativului s-a limitat numai la formele de plural tuturor (a) vs a/la toți/toate, iar variația formală \pm particula $-a$ se păstrează doar în cazul pronumelui (adjectivul excluzînd particula $-a)$.

La nivel sintactic, se înregistrează variația mai mare de topică a acestui cuantificator, permisă și în grupări care în limba actuală au topică fixă (de exemplu, tot + pronume personal, alternativul alt + tot), și variaţia structurilor cu tot sub raportul articulării substantivului cu care acesta se combină. Cuantificatorul tot a pierdut o serie de particularități sintactice specifice limbii vechi, dintre care cea mai evidentă este capacitatea de a selecta un substantiv nearticulat.

\footnotetext{
${ }^{9}$ A se compara exemplele (20o) și (20p), unde, deși substantivul cu care se construiește cuantificatorul este nearticulat (cias, podoabe), lectura este diferită: în (20o) nereferențială, iar în (20p) referențială. În română, absența articolului după prepoziție se poate corela cu citirea definită a numelui (Nedelcu, 2013, p. 459-461).
} 


\section{Bibliografie}

\section{A. Corpus}

AD.1722-5 = Antim Ivireanul, Didabii, în Opere, ed. G. Ștrempel, Editura Minerva, București, 1972.

Bvs.1763 = Vlad Boțulescu de Mălăiești, Scrieri, I. Viața lui Scanderbeg, ed. E. Timotin \& O. Olar, Editura Univers Enciclopedic Gold, București, 2013.

CazV.1643 = Varlaam, Cazania, ed. J. Byck, Fundația Regală pentru Literatură și Artă, București, 1943.

$\mathrm{CC}^{1} .1567=$ Coresi, Tîlcul evangheliilor, în Tîlcul evangheliilor și molitvenic românesc, ed. V. Drimba, Editura Academiei, București, 1998.

$\mathrm{CC}^{2} .1581$ = Coresi, Evanghelie cu invuățătură, în Carte cu învățătură (1581), vol. I, Textul, ed. S. Pușcariu \& Al. Procopovici, Atelierele Grafice Socec, București, 1914.

CDicț.1691-7 = Teodor Corbea, Dictiones latina cum valachica interpretatione, ed. A.-M. Gherman, Editura Clusium, ClujNapoca, 2001.

CIst.1700-50 = Constantin Cantacuzino, Istoriia Țărîi Rumâneşti, în Istoria Țărîi Rumânești atribuită stolnicului Constantin Cantacuzino, ed. O. Dragomir, Editura Academiei Române, București, 2006.

CL.1570 = Coresi, Liturghier, ed. Al. Mareș, Editura Academiei RSR, București, 1969.

ClM.1700-50 = Miron Costin, Letopisețul Țărîi Moldovei, în Opere, ed. P.P. Panaitescu, Editura de Stat pentru Literatură și

Artă, București, 1958.

CM.1567 = Coresi, Molitvenic, în Tîlcul evangheliilorși molitvenic românesc, ed. V. Drimba, Editura Academiei, București, 1998. $\mathrm{Cs}_{\mathrm{IV}} \cdot 1590-602, \mathrm{Cs}_{\mathrm{xI}} \cdot 1583-619, \mathrm{Cs}_{\mathrm{xv}} \cdot 1619$ = Codex Sturdzanus, ed. Gh. Chivu, Editura Academiei Române, București, 1993. Dî = Documente și însemnări românești din secolul al XVI-lea, text stabilit și indice de Gh. Chivu, M. Georgescu, M. Ioniță, Al. Mareș și Al. Roman-Moraru, Editura Academiei Române, București,1979.

DPar.1683 = Dosoftei, Parimiile preste an, Iași, 1683, ed. M. Ungureanu, Editura Universității „Alexandru Ioan Cuza”, Iași, 2012.

DRH,B = Documenta Romania Historica. B. Țara Românească, Editura Academiei Române, București, vol. XXXVIII (1653), 2009.

DVs.1682-6 = Dosoftei, Viața și petreacerea svinților, ed. R. Frențiu, Editura Echinox, Cluj-Napoca, 2002.

FD.1592-604 = Floarea darurilor, în Roman Moraru, Al. (ed.) (1996). Cele mai vechi cărți populare in literatura română, 1 ,

Editura Minerva, București.

FN.1693-704 = Foletul Novel. Calendarul lui Constantin Vodă Brîncoveanu (1693-1704), ed. E. Vîrtosu, Monitorul Oficial

și Imprimeriile Statului, București, 1942.

MC.1620 = Mihail Moxa, Cronograf, în Cronica universală, ed. G. Mihăilă, Editura Minerva, București, 1989.

NL 1750-66 = Ion Neculce, Letopisețul, în Ion Neculce, Letopisețul Țării Moldovei și O samă de cuvinte, ed. I. Iordan, Editura de Stat pentru Literatură și Artă, București, ed. a II-a, 1959.

NT.1648 = Noul Testament, Editura Reîntregirea, Alba Iulia, 1998.

PH.1500-10 = Psaltirea Hurmuzaki, ed. I. Gheție \& M. Teodorescu, Editura Academiei Române, București, 2005.

po.1582 = Palia de la Orăstie, ed. V. Pamfil, Editura Academiei Române, București, 1968.

Prav.1646 = Carte românească de invățătură, 1646, ed. A. Rădulescu, Editura Academiei, București, 1961.

Prav.1780 = Pravilniceasca condică, 1780, ed. A. Rădulescu, Editura Academiei, București, 1957.

sVI 1670 = Varlaam și Ioasaf, în Stanciu Istrate, M. (2013). Reflexe ale medievalității europene in cultura română veche: Varlaam și Ioasaf in cea mai veche versiune a traducerii lui Udriște Năsturel, Editura Muzeului Național al Literaturii Române, București.

șT.1644 = Șeapte taine a besearecii, Iași, 1644, ed. I. Mazilu, Editura Universităţii „Alexandru Ioan Cuza”, Iași, 2012.

\section{B. Referințe}

Croitor, B. (2015). Pronumele [Secolul al XIX-lea], în Chivu, Gh., Pană Dindelegan, G., Dragomirescu, A., Nedelcu, I. \& Nicula, I. (eds), Studii de istorie a limbii române. Morfosintaxa limbii literare in secolele al XIX-lea și al XX-lea, ediție revăzută și adăugită, Editura Academiei Române, București, p. 121-172 [ediția I: 2012].

Frâncu, C. (2009). Gramatica limbii române vechi (1521-1780), Casa Editorială Demiurg, Iași.

Giurgea, I. (2010). Pronoms, déterminants et ellipse nominale. Une approche minimaliste, Editura Universității din București, București.

Giurgea, I. (2013). The syntax of determiners and other functional categories, în Dobrovie-Sorin, C. \& Giurgea, I. (eds), A Reference Grammar of Romanian, volume 1: The Noun Phrase, John Benjamins Publishing Company, Amsterdam / Philadelphia, p. 97-174, Crossref.

Nedelcu, I. (2013). Prepositions and Prepositional Phrases, în Pană Dindelegan, G. (ed.), The Grammar of Romanian, Oxford University Press, Oxford, p. 451-465.

Nedelcu, I. (2015). Substantivul [Secolul al XIX-lea], în Chivu, Gh., Pană Dindelegan, G., Dragomirescu, A., Nedelcu, I. \& Nicula, I. (eds), Studii de istorie a limbii române. Morfosintaxa limbii literare in secolele al XIX-lea și al XX-lea, ediție revăzută și adăugită, Editura Academiei Române, București, p. 37-62 [ediția I: 2012]. 
Nicolae, Al. (2016). Cuantificatorul, în Pană Dindelegan, G. (ed.), Gramatica de bază a limbii române, Editura Univers Enciclopedic Gold, București, p. 374-378 [ediția I: 2010].

Pană Dindelegan, G. (2013). Flexiunea cazuală - intre analitic și sintetic. Cardinale și cuantificatori non-numerici în româna veche, în „Limba română”, vol. LXII, nr. 2, p. 159-173.

Stan, C. (2015). Proprietăți sintactice ale adjectivului tot în limba română veche, în Pomian, I. (coord.), Mocanu, N. (ed.), Inspre și dinspre Cluj. Contribuții lingvistice. Omagiu profesorului G.G. Neamțu la 70 de ani, Editura Scriptor și Editura Argonaut, Cluj-Napoca, p. 595-603.

Stan, C. (2016a). The article and other determiners, în Pană Dindelegan, G. (ed.), The Syntax of Old Romanian, Oxford University Press, Oxford, p. 288-304, Crossref.

Stan, C. (2016b). Pronominal quantifiers, în Pană Dindelegan, G. (ed.), The Syntax of Old Romanian, Oxford University Press, Oxford, p. 352-356, Crossref. 